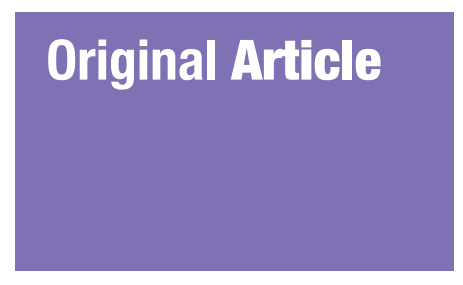

Submitted: 9 Nov 2015

Accepted: 13 May 2016

Online: 30 June 2016

\title{
Validation of Perceived Wellness Survey (PWS) in a Sample of Iranian Population
}

\author{
Mohammad Hossein KaveH ${ }^{1}$, Jeyran Ostovarfar ${ }^{2}$, Sareh \\ KeShavarzi $^{3}$, Leila Ghahremani ${ }^{4}$
}

1 Department of Health Education and Promotion, School of Health, Shiraz University of Medical Sciences, Shiraz, 7153675541 Iran

2 Department of Health Education and Promotion, School of Health, Shiraz University of Medical Sciences, Shiraz, 7153675541 Iran

3 Department of Epidemiology, School of Health, Shiraz University of Medical Sciences, Shiraz, 7153675541 Iran

4 Department of Health Education and Promotion, School of Health, Shiraz University of Medical Sciences, Shiraz, 7153675541 Iran

To cite this article: Kaveh MH, Ostovarfar J, Keshavarzi S, Ghahremani L. Validation of perceived wellness survey in a sample of iranian population. Malays J Med Sci. 2016; 23(4):46-53. doi: 10.21315/mjms2016.23.4.6

To link to this article: http://dx.doi.org/10.21315/mjms2016.23.4.6

\begin{abstract}
The individual's perception of health, when health is understood to include many dimensions of life, is considered the basis for any improvement in health status. Therefore, the present study aimed to assess the reliability and validity of the Persian version of the Perceived Wellness Scale (PWS) by applying it to employees of the Shiraz University of Medical Sciences. This cross-sectional study was conducted with 180 staff members of the university selected by convenience sampling. The study instrument was a Persian version of the PWS prepared through a translation and back-translation process. The reliability and validity of the instrument were assessed by using confirmatory factor analysis (CFA) and Cronbach's alpha coefficient. A total of 180 employees participated in the study. The mean age of the participants was 32.29 years $(S D=7.39)$ and $78.1 \%$ of the participants were women. The results showed that the Persian version of the PWS is acceptable. Cronbach's alpha coefficient was 0.87 for the whole scale, ranging from 0.68 to 0.85 on different dimensions of the scale. The results of split-half reliability and CFA indicated that the reliability and validity of the PWS are acceptable. The PWS is therefore an effective tool for evaluating the different dimensions of perceived wellness in the Iranian population.
\end{abstract}

Keywords: reliability and validity, survey, health, perception, Iran

\section{Introduction}

Health is a matter of importance for everyone as good health gives meaning to life enabling daily activities to be performed with strength and vigor (1). Health affects every dimension of life, including commitment to work, role in the family, social activities, personal interactions, and general well-being (2). Individuals' understanding of their own health, whether subjective, objective, or a combination of both, affects their decisions and behaviour regarding the maintenance, improvement, and restoration of their health (3). Evidence indicates that individuals' cognitions and perceptions of health have varied over time (4). Nelson and 
Simmons explain that for a long time medicine was concerned only with the body's physical status and the restoration of normal bodily functions after illness (5).

The way in which individuals perceive their own health and well-being is important because this affects their health (6). Perceived wellness refers to the individual's mental evaluation of their own health status. Perceived wellness shows the relationship between an overall evaluation of health and the level of healthcare needed and it is the most practical method of assessment used as an indicator of general physical health (7). Adams has pointed out that the concept of health is subject to relativity and subjectivity (8), and has therefore explained the dimensions of perceived health as follows:

The first dimension is physical health, which refers to the positive perceptions and expectations arising from physical health. Spiritual health is the second dimension, which refers to belief in the unifying force between body and mind, including a positive perception of the meaning and goal in life. Mental health reflects the perception that the individual desires to experience positive results from life events. Social health reflects the perception that support is available from family and friends. Emotional health reflects having a positive self-concept and self-esteem, where self-concept refers to an individual's internal image of self. Self-esteem is defined as valuing one's own self-concept (for instance, how much the individual values and loves him or herself). Finally, intellectual health is a reflection of the mental stimulation obtained through exposure to an optimum amount of intellectual stimulus (8).

In studies conducted in 1997, 1998, and 2000, Adams and colleagues used the Perceived Wellness Scale (PWS) to measure the health status of individuals. This scale uses 36 items to assess the six dimensions of perceived health. Not only does PWS assess individuals' perceived wellness, but it also evaluates their physical, mental, and spiritual status, as well as their social health expressed through their building of relationships with others. It was therefore used as a comprehensive questionnaire for investigating individuals' overall health status $(8,9,10)$. These studies showed that the PWS is an appropriate instrument for performing research and evaluating interventions in the area of perceived wellness. Other studies performed in South Africa and America also indicate that this instrument has acceptable reliability and validity $(11,12)$.
A review of the literature shows that no studies have as yet been conducted on the validation of PWS in Iran. This study therefore aimed to provide evidence for the validity and reliability of an Iranian version of the PWS, which could be used to measure wellness among the Iranian people. The aim of the study was to contribute to the existing literature on perceived wellness and to provide a tool for both researchers and health professionals to use in future research and practice.

\section{Materials and Methods}

A cross-sectional study was conducted on 180 academic staff members who had been working in the Shiraz University of Medical Sciences for at least two months during 2014. The study participants were selected through convenience sampling from the downtown colleges affiliated to the University, and they were requested to complete the PWS.

\section{Sample size determination}

The sample size was derived from the $\mathrm{N} / \mathrm{p}$ ratio, i.e. the item to participant ratio should be at least 1:5, indicating 5 responders for each question in the scale (13). The 36-item questionnaire therefore required a sample size of 180 participants.

\section{Measurement tools used in the study}

A two-part questionnaire was used to collect information for the study. The first part covered demographic information (age, gender, marital status) and the second part comprised the Persian PWS questionnaire.

The PWS, as designed by Adams, Benzer, Garner, and Woodruff (9), contains a total of 36 items. There are six items for each dimension: mental health $(1,7,13,19,25,31)$; emotional health $(2,8,14,20,26,32)$; social health (27, $33,3,9,15,21)$; physical health $(4,10,16,22$, $28,34)$; spiritual health $(5,11,17,23,29,35)$; and intellectual health $(6,12,18,24,30,36)$. Included are 21 positive and 15 negative items placed randomly throughout the questionnaire. The response for each item is given through a 6-point Likert scale. For the positive questions, scores of $6,5,4,3,2$, and 1 are assigned to "completely agree", "agree", "somewhat agree", "somewhat disagree", "disagree", and "completely disagree", respectively. The negative items are scored contrariwise. The score for each participant could range from 36 to 216, with higher scores representing a better perception of 
personal wellness. The score for each dimension is computed by the total score for that dimension divided by its number of questions (9).

Adams et al. provided information on use and scoring. In their research on PWS, they showed that the correlation between the subscales and the composite score ranged from 0.3 to 0.7 with an overall internal consistency of 0.91. In their pilot data they showed that the PWS had a convergent validity ranging from $\mathrm{r}=0.37$ to $\mathrm{r}=0.56$ (9).

\section{Persian translation of the Perceived Wellness} Survey

The translation of the PWS was done according to the four sequential stages of translation and back-translation as recommended by the World Health Organization (14). The translation instructions emphasized conceptual rather than literal accuracy and also the need to use a natural and therefore acceptable linguistic approach for the majority of Persian speaking participants. This meant an avoidance of technical terms and jargon.

The bilingual expert panel consisted of the original translator, experts in public health, and experts in the translation and development of questionnaires. The task of this panel was to sort out discrepancies and to arrive at a consensus regarding the translated version of the PWS.

The initial forward translation into Persian was back-translated into English by a single independent translator for whom English is the mother tongue and who had no knowledge relating to the questionnaire. The back-translated English version was then crossmatched with the original English PWS.

A pre-testing phase was carried out on ten participants from the same sampling group, but who would not be involved in the main study. The instrument was administered to the participants after a short explanation of the content. Face to face interview sessions were conducted by the primary investigator. The answers obtained from these sessions were matched with the actual responses given by the respondents on the questionnaire. The respondents were also interviewed regarding the questionnaire content and ease of understanding.

\section{Data collection}

When collecting the data, the researcher visited the colleges involved, introduced herself to the employees, and explained the study objectives. Regarding the ethical dimension, the participants were assured that their information would be kept confidential and their informed consent for taking part in the study was obtained orally. The Persian PWS was then given to the participants, and the questionnaires were answered anonymously. Inclusion criteria included the participants' interest in the study, their being on the staff of the Shiraz University of Medical Sciences, and their having an academic education. Exclusion criteria included an incomplete filling out of the questionnaire and a lack of interest in the study.

\section{Statistical analysis}

All statistical analyses were performed using the Statistical Package for the Social Sciences (SPSS) software (version 19) and LISREL8/8. In order to assess the reliability of the questionnaire, its internal consistency was determined. Internal consistency is an index that shows how many of the items of an instrument are related and homogeneous. Using this approach, a Cronbach's alpha coefficient of $\geq 0.7$ represents acceptable reliability for the instrument (15). The reliability of the PWS was also assessed using the split-half method , and the Spearman-Brown coefficient was calculated for the whole scale and for both halves. This index is normally used in cases where there is a large number of questions (16).

The Content Validity Ratio (CVR) was used to quantify the extent of the experts' agreement. A CVR score of .80 or higher indicates good content validity (17). In the Persian PWS the CVR score for each question was equal to or more than 0.6 and the CVR score for the total 36 items was calculated as .84. This was acceptable.

Confirmatory factor analysis was performed to ensure construct validity. Confirmatory factor analysis (CFA) specifies, in advance, the number of factors and the pattern of indicatorfactor loadings, as well as other parameters such as those bearing on the independence or covariance of the factors and indicators of unique variance (18). The CFA was utilised to test the fitness of the measurement model to confirm that the observed items were indeed measuring the latent constructs of interest. In doing this, the researcher made use of $\mathrm{x}^{2} / \mathrm{df}$, the goodness of fit index (GFI), and the root mean square error of approximation (RMSEA) among absolute fit indices, and the Tucker-Lewis fit index (TLI), the non-normal fit index (NNFI), and the comparative fit index (CFI) among other comparative fit indices. Using these tests, $\mathrm{x}^{2} /$ df $\leq 3$, CFI, TLI, and NNFI >0.9, and RMSEA $<0.08$, all showing the appropriateness of fit of 
the model $(19,20)$. Doll et al. and Baumgartner et al. also mention that an adjusted goodness of fit index (AGFI) of between 0.8 and 0.89 represents an appropriateness of fit for a model $(22,23)$. In addition to CFA, the inter-item reliability and comparison of known groups were utilised. In this method, the Pearson correlation coefficients are calculated for the subscales and values $\geq 0.4$ are considered valid correlations (21).

This study was approved by the ethics committee of the Shiraz University of Medical Sciences.

\section{Results}

Out of 216 employees, 180 completed the survey, with an overall response rate of $83 \%$. The participants ranged from 22-54 years old with a mean age of 32.29 years $(\mathrm{SD}=7.39)$. The mean working experience of the study participants was 9.22 years $(\mathrm{SD}=7.02)$. Most of the employees were female $(78.1 \%) ; 50 \%$ were married, $49.4 \%$ were single, and $0.6 \%$ were divorced.

\section{Reliability (internal consistency) of the questionnaire}

The internal consistency method and the computation of Cronbach's alpha coefficient were used to assess the reliability of the questionnaire and its dimensions. Based on the results, Cronbach's alpha coefficient was 0.87 (reliability) for the whole scale and $0.83,0.73,0.68,0.73$, 0.85 , and 0.82 for emotional, mental, social, physical, spiritual, and intellectual dimensions, respectively. In addition, using the SpearmanBrown correlation coefficient index, the reliability of the whole scale and the first and the second half was $0.85,0.87$, and 0.8 , respectively.

For a proper factor analysis, values higher than 0.7 are required in the KaiserMeyer-Olkin (KMO) measurement of sampling adequacy (22). The results indicated significance $(\mathrm{p}<0.001)$ with the appropriate values $\mathrm{KMO}=0.844$ (validity) for factor analysis .

\section{Confirmatory factor analysis}

As mentioned, considering the 6-factor and 36-item structure of perceived wellness survey (PWS) (each factor, including the six items), the confirmatory factor analysis (CFA), based on a structural equation, was used to assess and confirm the structural factors of this scale. The results of this analysis have been presented in Table 1. Accordingly, all of the calculated fitness indices were acceptable. The model presented in Figure 1 shows that all of the items were significant in their factors.

The validity of PWS was evaluated using Pearson's correlation coefficient. As Table 2 depicts, all of the subscales had significant strong or average correlations with each other $(\mathrm{p}<0.001)$. This indicated the construct validity of the test.

Table 1: Fitness indices of the Persian version of PWS based on CFA

$\begin{array}{llllllllll} & \text { X2 } & \text { Df } & \text { X2/df } & \text { P } & \text { AGFI } & \text { GFI } & \text { TLI/NNFI } & \text { CFI } & \text { RMSEA } \\ \text { Model } & 1092.30 & 579 & 1.88 & <0.0001 & 0.67 & 0.71 & 0.93 & 0.93 & 0.070\end{array}$

Abbreviations: GFI (goodness of fit index), AGFI (adjusted goodness of fit index), TLI/NNFI (Tucker-Lewis fit index/non-normal fit index), CFI (comparative fit index), RMSEA (root mean square error of approximation)

Table 2: Correlations among the PWS factors

\begin{tabular}{lcccccc} 
Factor & Mental & Emotional & Social & Physical & Spiritual & Intellectual \\
Mental & 1 & & & & & \\
Emotional & $0.54^{*}$ & 1 & & & & \\
Social & $0.42^{*}$ & $0.44^{*}$ & 1 & & & \\
Physical & $0.44^{*}$ & $0.50^{*}$ & $0.43^{*}$ & 1 & & \\
Spiritual & $0.58^{*}$ & $0.71^{*}$ & $0.45^{*}$ & $0.50^{*}$ & 1 & \\
Intellectual & $0.50^{*}$ & 0.65 & $0.45^{*}$ & $0.54^{*}$ & $0.68^{*}$ & 1 \\
\hline
\end{tabular}

${ }^{*} \mathrm{p}<0.001$ 


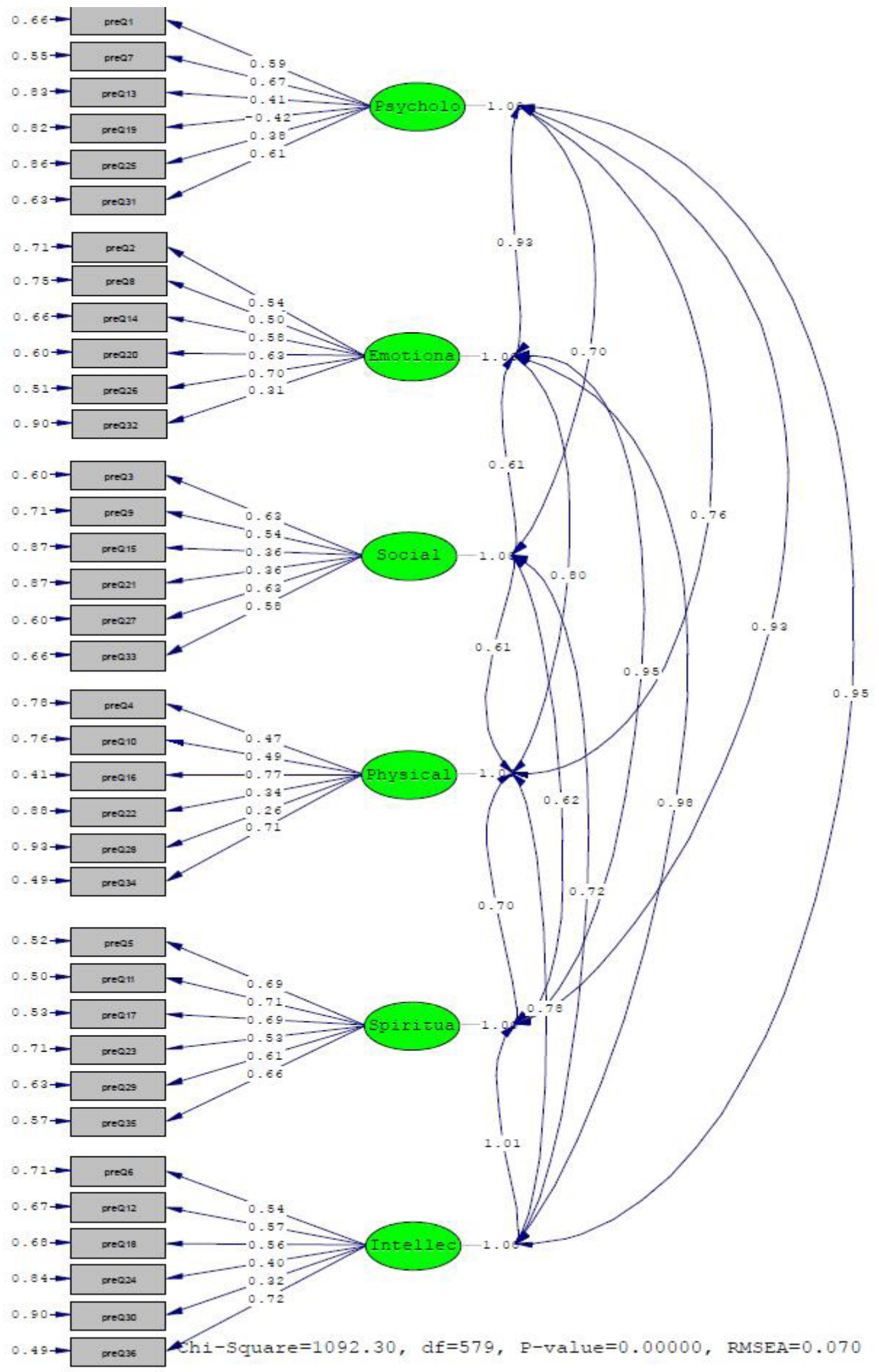

Figure 1: Factor loadings and correlations among the factors based on the results of the CFA of the Persian version of PWS 


\section{Discussion}

The results of the content validity analysis revealed that the Persian version of PWS followed a proper and logical trend.

Reliability means repeatability, and it is assessed through various methods (23). In the present study, reliability was evaluated using internal consistency and split-half methods. Cronbach's alpha coefficient was used to determine the internal consistency. In the splithalf method, questions with even numbers in one test and questions with odd numbers in another test were considered. Then, the reliability coefficient was assessed using the Spearman-Brown method. According to the results, the Cronbach's alpha coefficient and the Spearman-Brown correlation coefficient were $\mathrm{a}=0.87$ and $\mathrm{r}=0.85$, respectively, indicating the acceptable reliability of the scale. Similarly, Rothmann and Ekkerd conducted a study on the staff of the police department in South Africa and reported the appropriate reliability of this scale ( $\alpha=0.74-0.81)$ (11). In addition, Adams et al., who designed the questionnaire, performed studies on three different groups; they reported that Cronbach's alpha coefficients ranged from $0.88-0.93$ and obtained $\alpha=0.91$ for the whole samples (8).

In the current study, Cronbach's alpha coefficient of the social dimension was 0.68 , which was in contrast to the other dimensions (above 0.7). In Adams et al.'s study, Cronbach's alpha coefficient of social and intellectual dimensions was 0.64 , which contrasted to studies of other dimensions (above 0.7).(8) In addition, KMO was obtained as 0.844 in this study, which agreed with the research by Rothmann and Ekkerd $(\mathrm{KMO}=0.85)(11)$. Moreover, the split-half correlation coefficient was 0.85 for the whole scale, 0.87 for the first half, and 0.8 for the second half. In contrast, Adams et al. assessed the split-half correlation coefficients for all of the dimensions separately: $0.71,0.68,0.62,0.52,0.61$, and 0.53 for physical, spiritual, mental, social, emotional, and intellectual dimensions, respectively (8).

The results of CFA showed the acceptable fitness of the scale. Accordingly, $\mathrm{X}^{2} / \mathrm{df}=1.88$, GFI = 0.71, CFI $=0.93, \mathrm{TLI} / \mathrm{NNFI}=0.93$, and RMSEA $=0.070$ were consistent with the measures announced by Doll et al. and Baumgartner et al. (24). This revealed an unchanged structure of the questionnaire through the translation process. In the factor analysis, all of the items were placed on the relevant components.
Pearson's correlation coefficient demonstrated positive mild to strong correlations among all of the dimensions of the scale $(\mathrm{r}=0.42-0.71)$. In contrast, Adams et al. reported that the correlation coefficients of the subscales ranged from $0.3-0.70(8)$

The results of the PWS Persian version have satisfactory reliability and validity. This could serve as a starting point for research regarding the measurement of PWS in Iran.

\section{Limitation}

Due to the dispersion of the colleges of Shiraz University of Medical Sciences, the samples were conveniently selected, sampling from the staff working in the colleges located downtown.

Since limited references were found regarding the reliability and validity of this scale, only the available references were examined in the discussion section.

\section{Recommendation}

A reliable, equivalent, and valid measure of perceived wellness could help assess the prevalence of wellness in Iran. Therefore, a representative random sample of the Iranian employee population should be surveyed. Longitudinal research and trend studies are recommended to establish this. More research is also needed regarding the dimensions of perceived wellness in different language groups.

\section{Acknowledgement}

This article was extracted from Jeyran Ostovarfar's M.Sc thesis in Health Education and Health Promotion. It was financially supported by the Research ViceChancellor of Shiraz University of Medical Sciences in Shiraz, Iran (grant No. 93-7315). The authors are grateful for the participation of all of the staff of Shiraz University of Medical Sciences.

\section{Conflict of Interest}

None

\section{Funds}

It was financially supported by the Research ViceChancellor of Shiraz University of Medical Sciences in Shiraz 


\section{Authors' Contribution}

The conception and design, drafting of the article, critical revision of the article for important intellectual content, final approval of the article:MHK

The conception and design, drafting of the article, provision of study materials or patients, collection and assemblv of data: JO

Analysis and interpretation of the data, statistical expertise: SK

The drafting of the article, administrative, technical, or logistic support.: LG

\section{Correspondence}

Dr. Mohammad Hossein Kaveh

$\mathrm{PhD}$

Department of Health Education and Promotion,

School of Health, Shiraz University of Medical Sciences, Shiraz, 7153675541 Iran

Tel: +987137251001

Fax: +987137260225

Email:kaveh@sums.ac.ir

\section{References}

1. Jourdan PJ, Norman GJ, Rossi JS. Integration attitude with decisional balance as predictors of stage of change for exercise. Psycho of Sport and Exercise. 2008;3:65-85.

2. Cheng H, Furnham A. Factors influencing adult physical health after controlling for current health conditions: Evidence from a British Cohort. PloS one. 2013;8(6):e66204. http://dx.doi.org/10.1371/ journal.pone.0066204

3. Foster LT, Boomer J, Keller CP. The British Columbia atlas of wellness: Western Geographical Press; 2007.

4. Bettina FP. Bak. Children's perceptions of health and illness: Images and lay concepts in preadolescence. Health Education Research. 2006;21(5):643-653. http://dx.doi.org/10.1093/her/cylo34

5. Nelson DL, Simmons BL. Health psychology and work stress: A more positive approach. Washington, DC, US: American Psychological Association. 2003:97-119.

6. Scriven A. Promoting health: A practical guide. Forewords: Linda Ewles \& Ina Simnett; Richard Parish: Elsevier Health Sciences; 2010.

7. Kim ON, Oh JW, Kim YS, Kim HW, Lee MY, Ha SH. Impacts of perceived health status and self-efficacy in hospital nurses on their health promoting behaviors. Advances in information Sciences and Service Sciences (AISS). 6(1):139-144.
8. AdamsT,BeznerJ,SteinhardtM.Theconceptualization and measurement of perceived wellness: Integrating balance across and within dimensions. American Journal of Health Promotion. 1997;11(3):208-218. http://dx.doi.org/10.4278/0890-1171-11.3.208

9. Adams T, Benzer J, Garner L, Woodruff S. Construct validation of the perceived wellness survey. American Journal of Health Studies. 1998;14:212-219.

10. Adams TB, Bezner RJ, Drabbs ME, Zambarano RJ. Steinhardt MA. Conceptualization and measurement of the spiritual and psychological dimensions of wellness in a college population. Journal of American College Health. 2000;48:165-173.http://dx.doi. org/10.1080/ 07448480009595692

11. Rothmann S, Ekkerd J. The validation of the perceived wellness survey in the South African police service. SA Journal of Industrial Psychology. 2007;33(3):3542. http://dx.doi.org/10.4102/sajip.v33i3.393

12. Harari MJ, Waehler CA, Rogers JR. An empirical investigation of a theoretically based measure of perceived wellness. Journal of Counseling Psychology. 2005;52(1):93. http://dx.doi.org/ 10.1037/0022-0167.52.1.93

13. Henrica CW, de Vet Herman J, Ade`r CB, Terwee, Power F. Are factor analytical techniques used appropriately in the validation of health status questionnaires? A systematic review on the quality of factor analysis of the SF-36. Quality of Life Research. 2005; 14: 1203-1218. http://dx.doi.org/10.1007/ s11136-004-5742-3

14. World Health Organization, Protocol for translation back-translation. Available online at http://www.who. int/substance_abuse/research_tools/translation/ en/. Accessed on 15/05.2015

15. Jones G BK, Clark T, Denham R, Holder M, Haynes T, et al. The Polycystic Ovary Syndrome Health-related Quality of Life Questionnaire (PCOSQ). Human Reproduction. 2004;2(19):371-377. http://dx.doi. org/10.1093/humrep/deho48

16. Saif AA. Educational measurement, assessment and evaluation. Tehran: Doran Press; 2004.

17. Lawshe $\mathrm{CH}$. A quantitative approach to content validity. Personnel Psychology, 1975: 28(4): 563575. http://dx.doi.org/10.1111/j.1744-6570. 1975. tbo1393.x

18. Brown TA. Confirmatory factor analysis for applied research. Spring Street, NY: The Guilford Press; 2006.

19. Baumgartner H HC.Applications of structural equation modeling in marketing and consumer research. A review. Int $J$ Res Market. 1996;13(2):139-161. http://dx.doi.org/10.1016/ 0167-8116(95)ooo38-o

20. Doll W XW, Torkzadeh G. A confirmatory factor analysis of the end-user computing satisfaction 
Original Article | Validation of Perceived Wellness Survey

instrument. MIS Quarterly. 1994;18(4):453-461. http://dx.doi.org/10.2307/249524

21. Badiyepeymaye, Jahromi Z KS, Jahanbin I. Determination of the reliability and validity of the Persian version of nurses' self-concept questionnaire (NSCQ). Nursing Education. 2014;2(4):63-71.

22. Houman H. Multivariate data analysis in behavioral research. Tehran: Parsa pub; 2001.
23. Kaplan RM, Sacuzzo DP. Psychological testing: Principles, applications, and issues. 8th ed. Independence, KY: Cengage Learning; 2013.

24. Alawi GA. Synchronous of ICT and e-learning in Yemen: Impact and usability. Merit Research Journal of Education and Review. 2014;2(1): 8-14. 